\title{
Methods for Determining the Epicenter of Strong Earthquake
}

\author{
Giulio Riga, Paolo Balocchi \\ Geologist, Independent Researcher, Italy \\ Email: giulio.riga@tin.it
}

How to cite this paper: Riga, G. and $\mathrm{Ba}$ locchi, P. (2021) Methods for Determining the Epicenter of Strong Earthquake. Open Journal of Earthquake Research, 10, 42-67. https://doi.org/10.4236/ojer.2021.102004

Received: March 15, 2021

Accepted: May 4, 2021

Published: May 7, 2021

Copyright $\odot 2021$ by author(s) and Scientific Research Publishing Inc. This work is licensed under the Creative Commons Attribution International License (CC BY 4.0).

http://creativecommons.org/licenses/by/4.0/

\begin{abstract}
The analysis of seismic sequences is the primary objective for the study of the evolution of seismicity in a particular area, in order to determine a greater awareness of its seismogenic potential. The eventual determination of the epicenters of future earthquakes associated with the expected magnitude can be the tool to better seismic prevention. In this paper, we present some procedures for epicenter prediction of a strong earthquake, developed after a careful analysis of the fluctuations of latitude and longitude values in time and space and distance, between seismic events occurred in a specific area. By analyzing several seismic sequences, whose data have been taken from the numerous catalogs on seismicity, we noticed that the epicenters of the earthquakes that precede the strongest ones, tend to converge towards the epicenter where the strong earthquake will happen, following a pattern and a repetitive directional trend. Analysis of the pattern and trend, which represent the fluctuation of events and distances between pairs of earthquakes, has allowed us to localize the epicentral area of a future earthquake, which more reliably complements the other forecasting methods we have developed in the past. Retrospective tests performed on past seismic sequences have shown that the predictive procedures developed are able to identify in a simple way and in the short term, the area where a strong earthquake is most likely to occur.
\end{abstract}

\section{Keywords}

Dynamicepicenter, Mainshock, Seismic Sequence

\section{Introduction}

Short-term prediction of the epicenter of a future earthquake is an important feature for seismic hazard mitigation by opening the possibility of preventing considerable damage. 
Accurately determining the epicenter location is very difficult [1] [2] [3]. Zhu [3] proposed a new estimation algorithm for the epicenter location using low frequency seismograms.

Some studies have suggested that the location and magnitude distribution of foreshocks are different from the distribution of other earthquakes [4] [5] [6] and show correlations between the size and location of the foreshock zone and that of the subsequent mainshock [7] [8] [9] [10]. These observations are consistent with a scenario where foreshocks are the manifestation of a seismogenic process leading to mainshock nucleation [11] [12].

The evolution analysis of seismicity at the regional scale, shows that just before the main earthquakes there is a characteristic change in the sequence. This change, however, can be identified when the seismic data are analyzed in a new time domain termed "natural time" [13].

Observations related to the fluctuations of seismicity related to time and space can provide important information for determining the location of a future strong earthquake in the short term.

For this purpose, retrospective analysis of the epicenters of aftershocks can be used to improve estimates of the epicenter of short-term strong earthquakes.

The hypothesis that seismic activity is concentrated before a strong earthquake is valid for many large seismic events that have occurred in various parts of the world and is supported by the distribution of minor aftershocks in an area that can be considered to have a greater instability [14].

In fact, the analysis of the positions of the epicenters of the shocks between the first maximum and the second maximum of the foreshocks-mainshock-aftershocks sequence(FMA) [14] of which one or more foreshocks are part, it is logical to expect that the position of some of them are close to that of the expected strong earthquake (EQ).

Most quakes before an EQ are concentrated near the foreshocks, but in some situations, they may nucleate at greater distances.

These features suggest that clustering of shocks, including some foreshocks that form before the EQ, is not always accompanied by a major energy release in the same area.

This sudden variation in the location of the epicenter of the expected EQ perhaps is due to the accumulation of static and dynamic stress generated by the premonitory shocks. According to Stein [15] the earthquake is not an isolated phenomenon, but part of its energy is able to move along the fault accumulating along other nearby faults to give rise to new earthquakes. Seismicity would have a "chain" behavior, i.e., faults would be highly susceptible to stresses acquired as a result of seismic events that affected nearby faults.

The detailed analysis of whole seismic sequences shows that earthquakes do not occur in a totally random manner, but often tend to cluster both in space and time [16] at all levels of magnitude forming a seismic cluster characterized by a directional trend that allows to identify the epicenter of a future strong earthquake. 
In particular, the organization in space and time of the latitude and longitude values of seismic events is probably the most suitable tool to identify the area most likely to be hit by a strong earthquake.

The location of the future EQ is strongly dependent on the size of the area analyzed. The smaller the size of the area, the more accurate is the result obtained. Therefore, it is necessary to proceed by analyzing the seismicity first of a large area and then of a smaller area included in the former.

In the proposed models (Figure 1), the location of the EQ is estimated using some simple algorithms based on the spatio-temporal location of the tremors preceding the strong future earthquake.

The analysis procedures tend to identify one or more possible areas in the analyzed region and their filtering to reduce the prediction error.

The algorithms were designed by retrospective analysis of 130 seismicity models preceding earthquakes of magnitude $M \geq 7$ and 40 of magnitude between $6-6.9 \mathrm{M}$, occurring in various areas of the mode (Figure 2) and using the catalogs of the National Institute of Geophysics and Volcanology (INGV) [17] and the U.S. Geological Survey (USGS) [18] and Japan (NIED) [19].

The number of earthquakes in the seismicity models varied from a minimum of 40 to a maximum of 100 events. The minimum magnitude and maximum hypocentral depth used were $2.0 \mathrm{M}$ and $50 \mathrm{~km}$, respectively.

Analyses were performed with the experimental software "Previsio"-Epicenter section made by the authors.

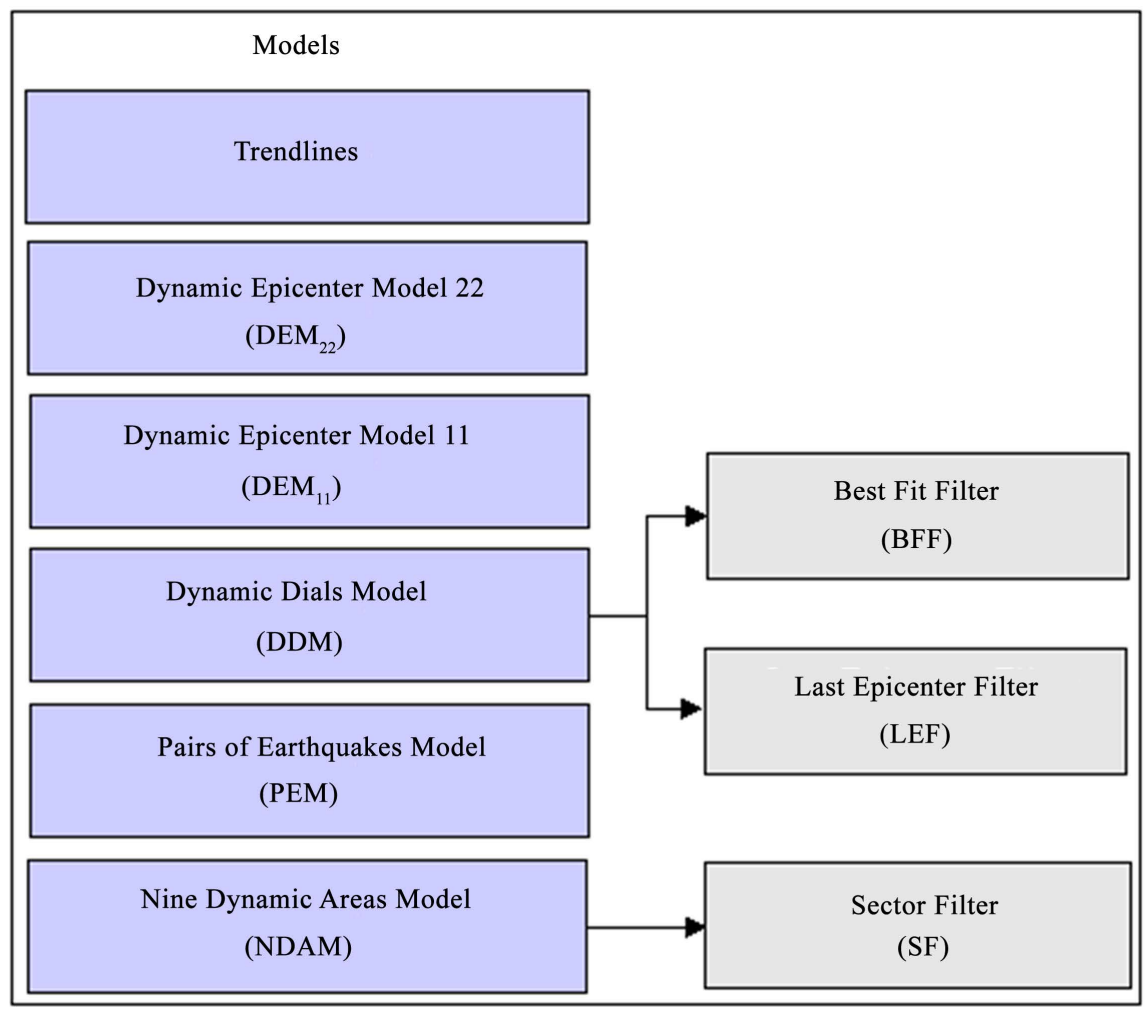

Figure 1. Models and experimental filters used for sequence analysis. 


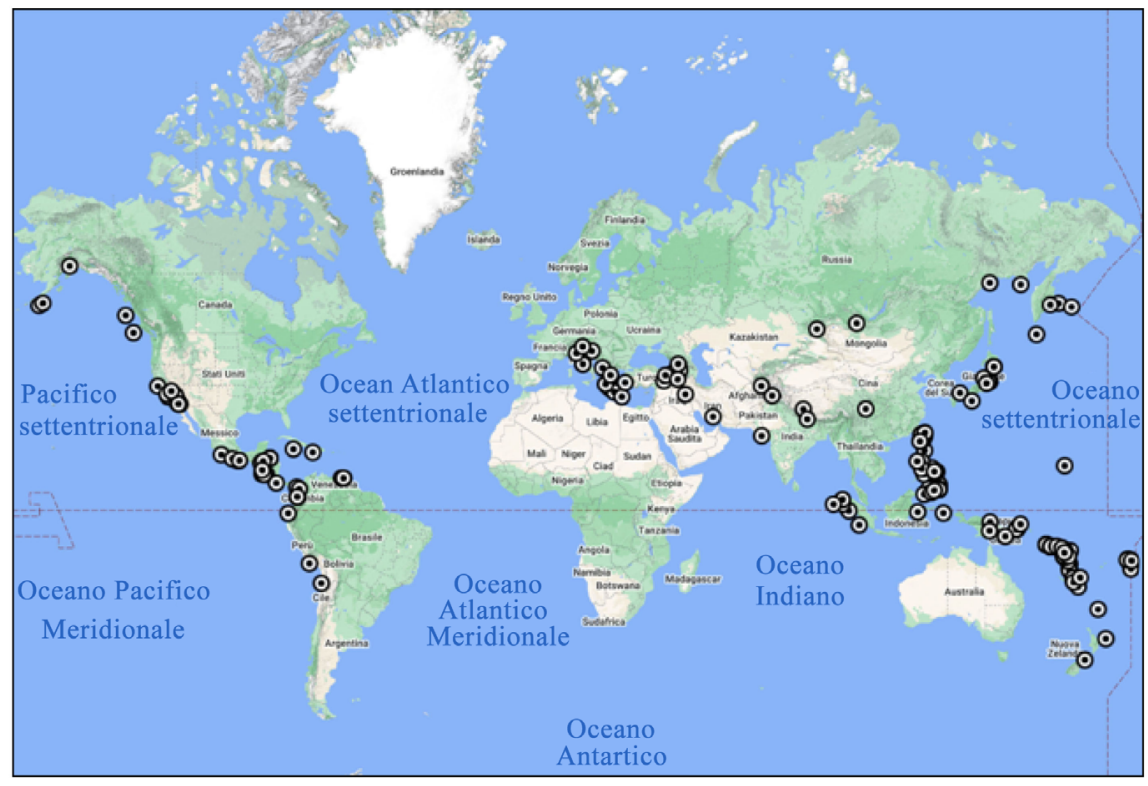

Figure 2. Map of the epicenters of the analyzed sequences.

\section{Methodologies}

\subsection{Trendlines Model}

The distribution of latitude and longitude data of earthquakes preceding strong events, within an area, shows an evolution of the dynamical system in space and time with trajectories through ordered geometry that tend to cluster regularly according to clusters.

These trajectories of latitude and longitude values and the spatial and temporal clustering during the seismic activity, can be used to predict or to have information in the short term on the occurrence of a strong EQ and on the epicentral area where it will happen.

Analyzing the seismic sequence, the most frequent pattern is the triangular pattern (Figure 3) with sides having different inclination, where in the terminal part the values decrease rapidly.

Moreover, in many seismic sequences it has been found that over time, the position of the future earthquake tends to move in the vicinity of the last earthquake occurred in the examined area.

The onset of the values tending to concentrate indicates the time when the system enters the critical phase, with a lead time of days or several months from the occurrence of the main EQ.

This tendency of latitude and longitude values to cluster was found in $70 \%$ of the analyzed sequences.

The trendlines model is designed to identify the area where a strong EQ will occur with an acceptable error value.

In fact, in our approach, the analysis of the position of the epicenters of the quakes preceding the EQ allows with a certain reliability to identify the area where, in the short term, a strong earthquake is likely to occur and to have 


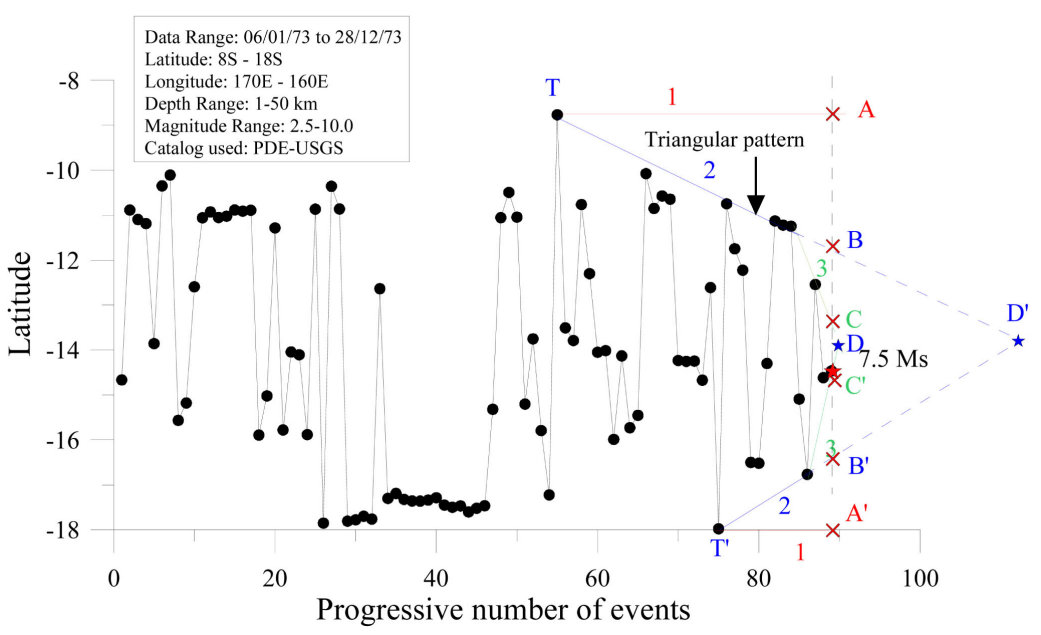

Figure 3. The latitude values of seismic sequence of Vanuatu earthquake in 28/12/73. The graphical interpretation of trendlines 1, 2, 3 with different inclination (red, blue and green color lines) show the trend of latitude value in the time. The red-colored, blue colored stars indicate the earthquake epicenter, by the order trendlines respectively. The letters T, D' and T' indicate the triangular pattern.

information on the beginning of the critical stage of the seismic sequence.

The information on the size of the area and the location of the epicenter of the expected EQ is obtained by analyzing the fluctuations of the latitude and longitude values of the seismic events occurred in the identified area through the trendlines.

The trendlines are a tool that allows to identify with greater clarity the evolution of the values of latitude and longitude of seismicity, and any change in the trendline represents an alert signal on the acceleration or deceleration of the trend in place.

A trendline is a line identifiable visually and graphically that connects at least two or more points of minimum or maximum during a phase of long, medium or short period and also shows how the values move within channels usually marked by parallel or inclined trendlines.

Observing the sequences of latitude and longitude values shown in Figure 3 and Figure 4, it can be seen that before the $\mathrm{EQ}$, there are often several trendlines with different angles converging towards the point that could represent the future epicenter of the strong earthquake.

The trendlines with lower inclination give indications on the medium/long term, while those with higher inclination give information on the short term.

This analytical approach can be used to get information in the short term on the occurrence of the next strong earthquake.

In fact, from the graphs it is possible to observe that when the values do not seem to respect the trendline with a smaller inclination, we can expect the occurrence of an earthquake more or less strong, sometimes preceded by trendline with a smaller inclination (for example during the formation of a cluster after a foreshock). 


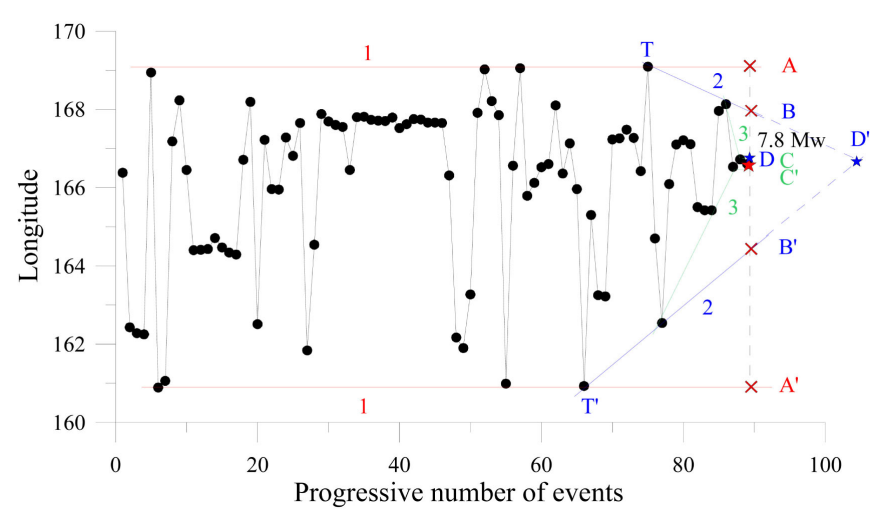

Figure 4. The longitude values of seismic sequence of Vanuatu earthquake in 28/12/73. The graphical interpretation of trendlines 1, 2, 3 with different inclination colored, show the trend of longitude values in the time. For explanation see caption of Figure 1.

In the figures, the letters $\mathrm{AA}^{\prime}, \mathrm{BB}^{\prime}$ and $\mathrm{CC}^{\prime}$ indicate the latitude and longitude values of the epicentral areas defined by the trendlines prolonged to the time of occurrence of the 1973 Vanuatu earthquake of magnitude $7.5 \mathrm{Ms}$, while the points $\mathrm{D}$ and D' of intersection of the second and third order trendlines, indicate the latitude and longitude value of the epicenter of the expected EQ.

Therefore, the convergence of the upper and lower trendlines shows predictive significance, since the meeting point defines the longitude and/or latitude of the epicenter.

Figure 5 shows the areas obtained with this procedure (areas 1, 2 and 3), the location of the meeting point of the trendlines and the epicenter of the earthquake.

Figures 6-8 show the latitude and longitude values and the epicenter areas defined by the trendlines extended to the 2009 L'Aquila earthquake of magnitude 6.1 Mw.

Figure 9 shows an example that illustrates how to draw the trendlines when the maximum and/or the absolute minimum (point $\mathrm{M}$ ) are at the end of the series of values analyzed. In this case, the lower first-order trendline (red-colored line) is used to plot the relative minimum M1.

\subsection{Dynamic Epicenter Model 22 (DEM 2 )}

The model tries to understand what the trend of values in the short term will be, in order to predict the epicenter of a strong EQ.

The working hypothesis is that the last 21 earthquakes occurred in an area allow to know which the current trend is and eventually allow to determine the coordinates of the epicenter of the expected earthquake.

The procedure includes the following calculation steps:

Step 1. Calculate the line that interpolates (best-fit line) the longitude and latitude values using the last 21 earthquakes that occurred in the analyzed area;

Step 2. Calculate the longitude $\left(\mathrm{LONG}_{22}\right)$ and latitude $\left(\mathrm{LAT}_{22}\right)$ of the expected earthquake (the 22nd) using the equation of the best-fit line (Figure 10 and Figure 11); 


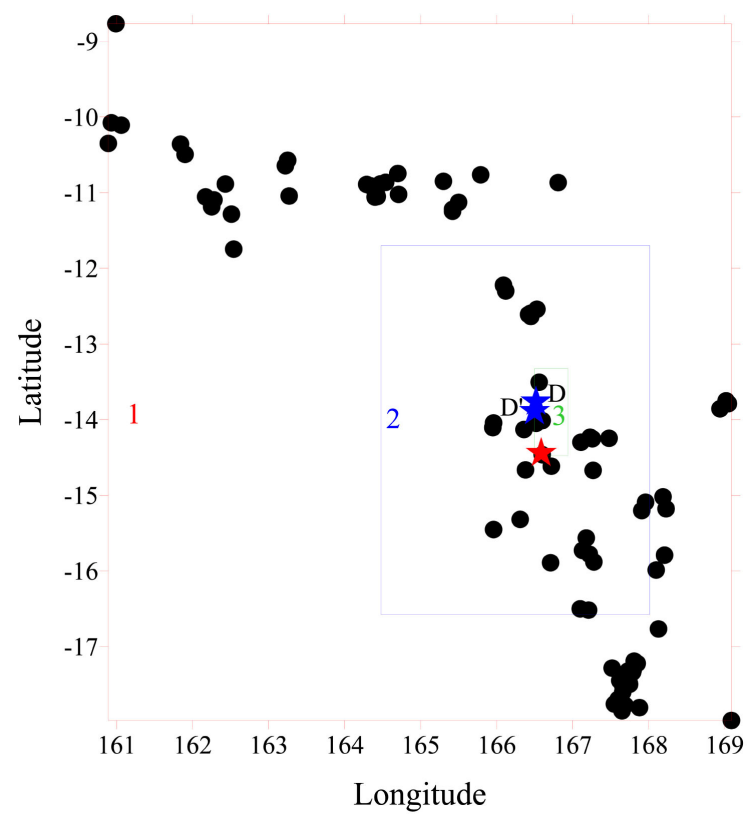

Figure 5. Vanuatu earthquake of 28/12/73. The red, blue and green boxes indicate the areas defined by the first, second and third order trendlines. The red color star indicates the epicenter of the earthquake that actually occurred, the blue color stars indicate the epicenters defined by the second (D) and third (D') order trendlines.

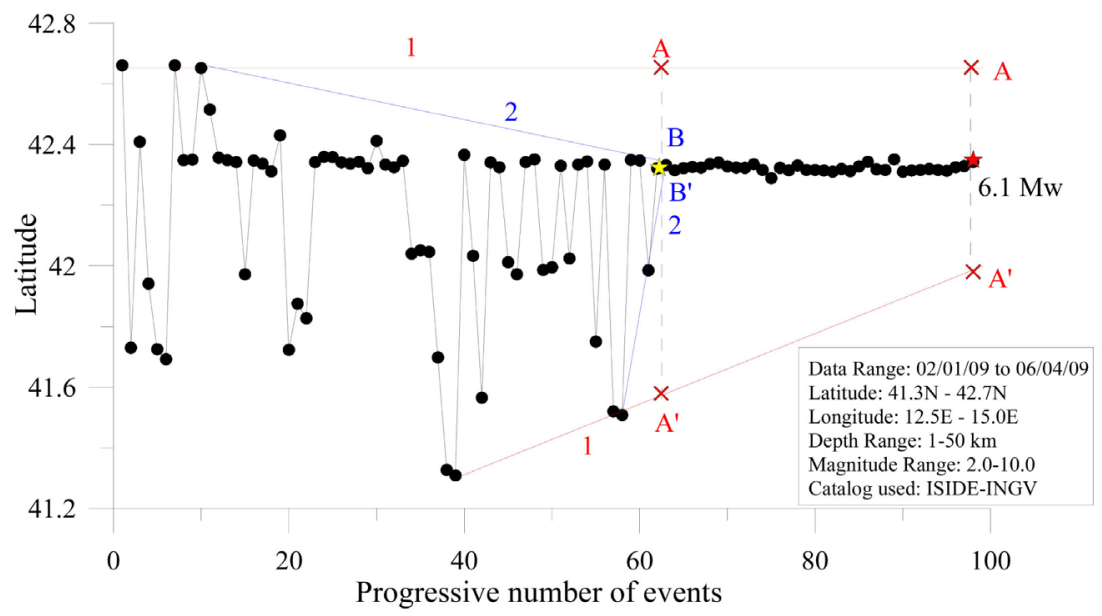

Figure 6. The latitude value of L'Aquila earthquake in 06/04/09. The graphical interpretation of order trendlines with different colors. The red colored star indicates the longitude value of the earthquake epicenter, the yellow colored star indicates the epicenter defined by the second order trendlines.

Step 3. Report the coordinate point $\left(\mathrm{LONG}_{22}\right)$ and $\left(\mathrm{LAT}_{22}\right)$ on the plan of the epicenters of the earthquakes that occurred in the analyzed area (Figure 12).

In case the last three values of latitude and/or longitude of the analyzed series are distant $\mathrm{L} \leq 0.35$ (longitude or longitude deviation) their average is assumed to calculate the position of a second dynamic epicenter of the EQ.

Figure 13 shows the dynamic epicenter $\left(\mathrm{LONG}_{22}\right)$ and $\left(\mathrm{LAT}_{22}\right)$ of the 1975 Philippine earthquake. 


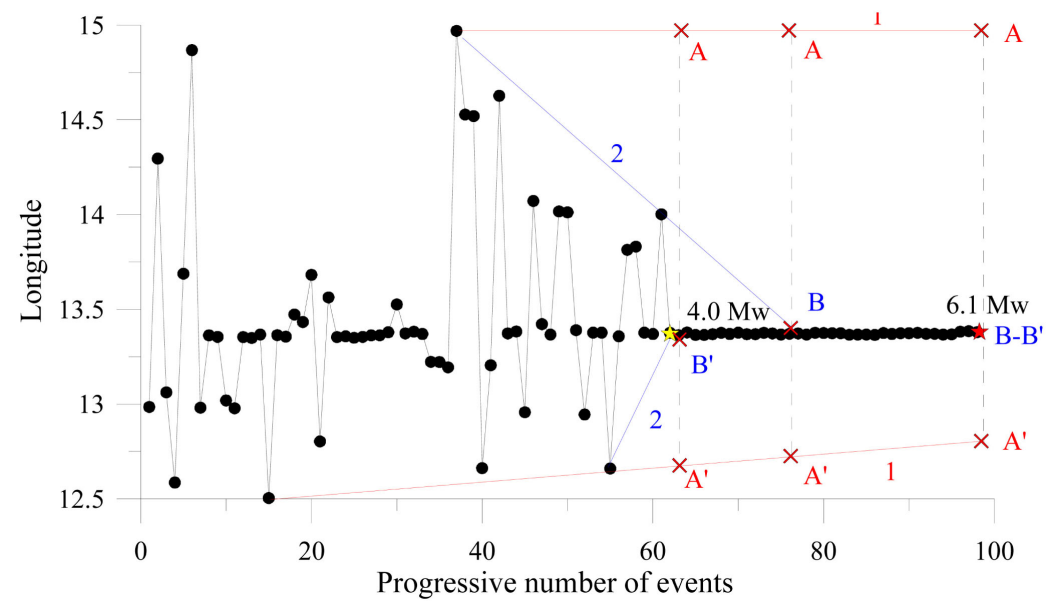

Figure 7. The latitude value of L'Aquila earthquake in 06/04/09. For explanation see caption of Figure 4.

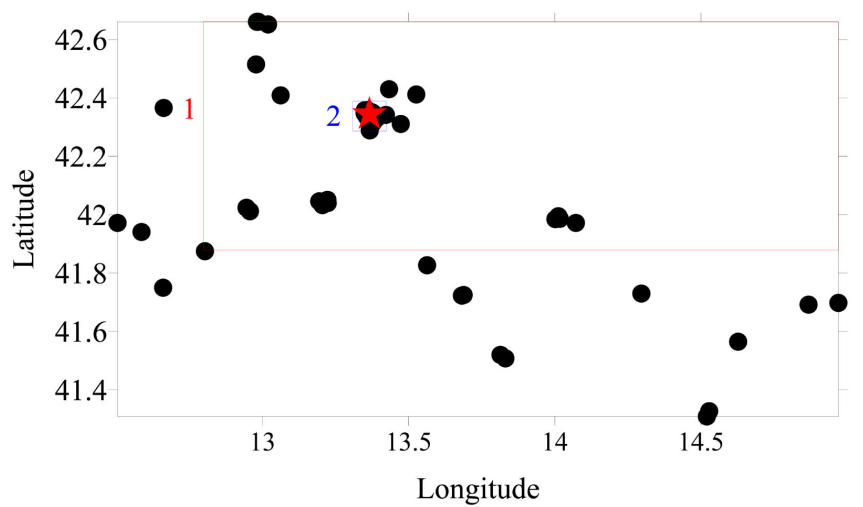

Figure 8. L'Aquila earthquake of 06/04/09. The red and blue boxes indicate the areas defined by the first and second order trendlines. The red star indicates the epicenter of the earthquake that actually happened.

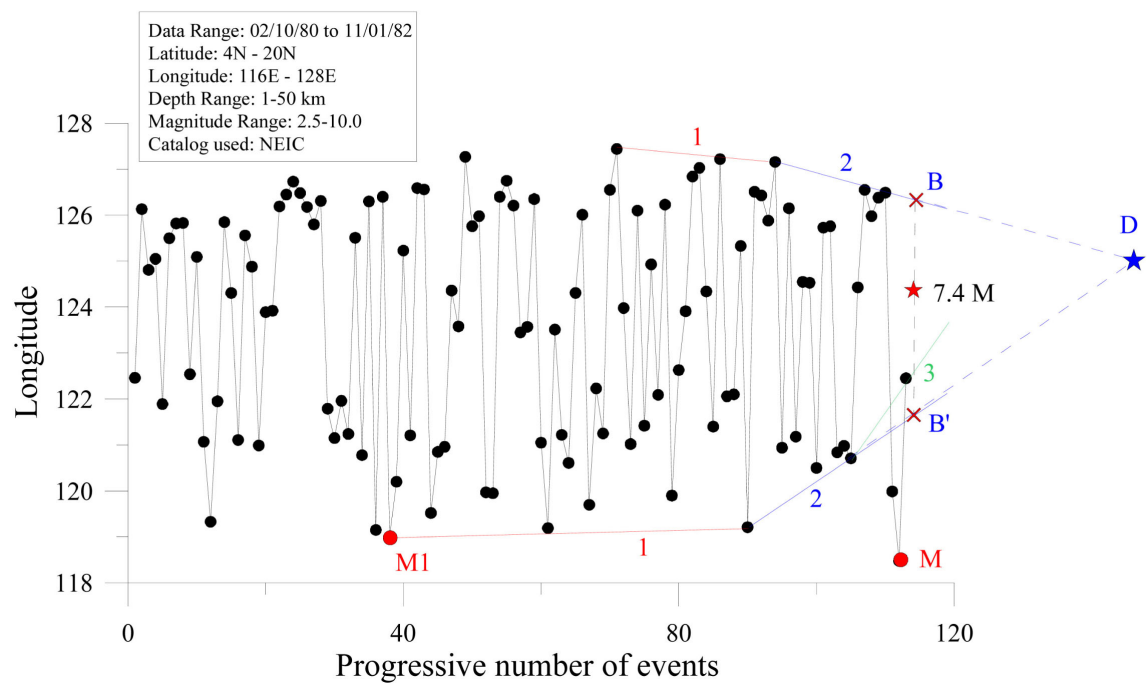

Figure 9. The longitude values of Philippine earthquake in 11/01/1982. The graphical interpretation of order trendlines with different colors. The red star indicates the earthquake epicenter, the blue star indicates expected earthquake epicenter. 


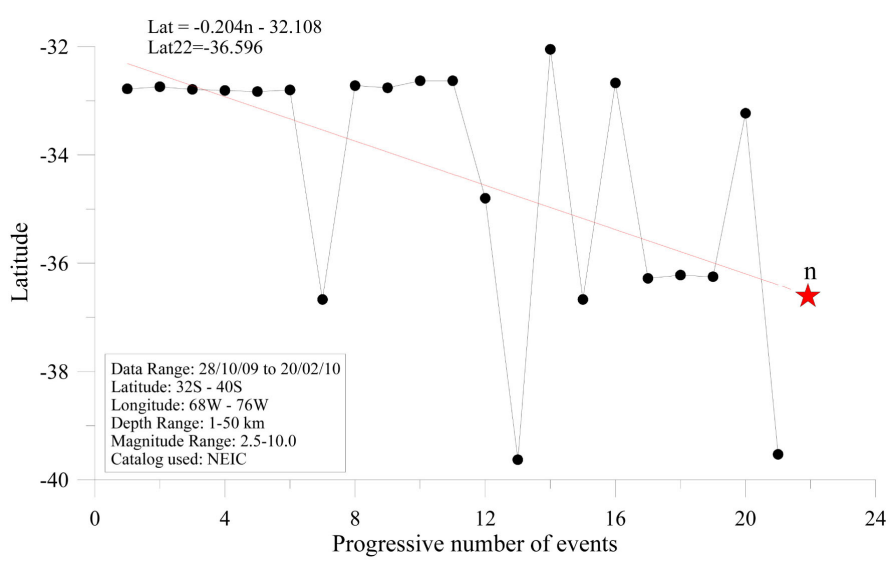

Figure 10. Latitude values of Chile earthquake in 27/02/2010. The red colored line indicates the best-fit line of value. The red colored star indicates the expected earthquake.

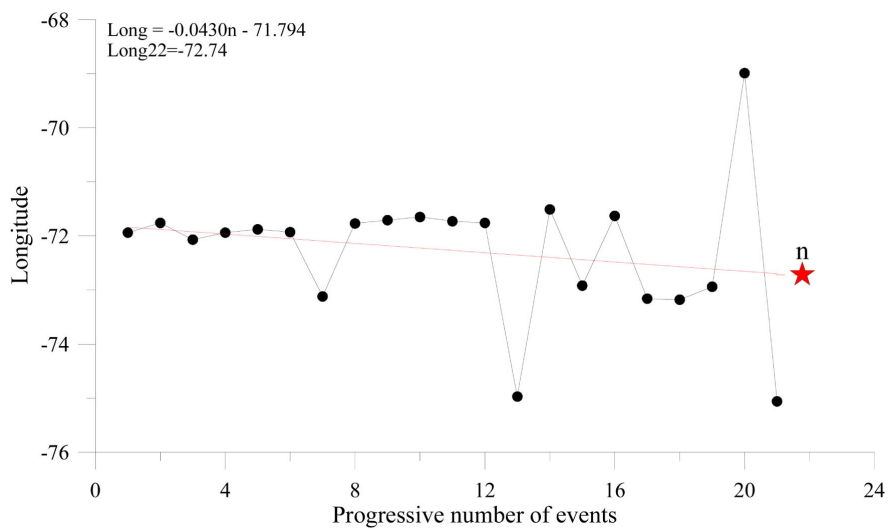

Figure 11. Longitude values of Chile earthquake in 27/02/2010. For explanation see caption of Figure 8.

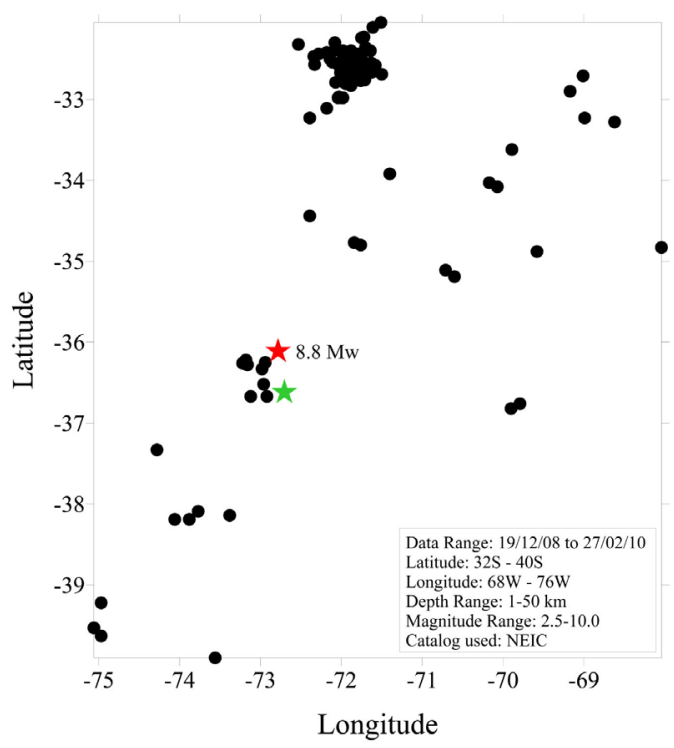

Figure 12. Chile earthquake of 27/02/2010 with the analyzed seismicity indicated with black circles. The location of the dynamic epicenter $\mathrm{DEM}_{22}$ indicated with the green color star, while the red color star indicates the epicenter of the mainshock occurred. 


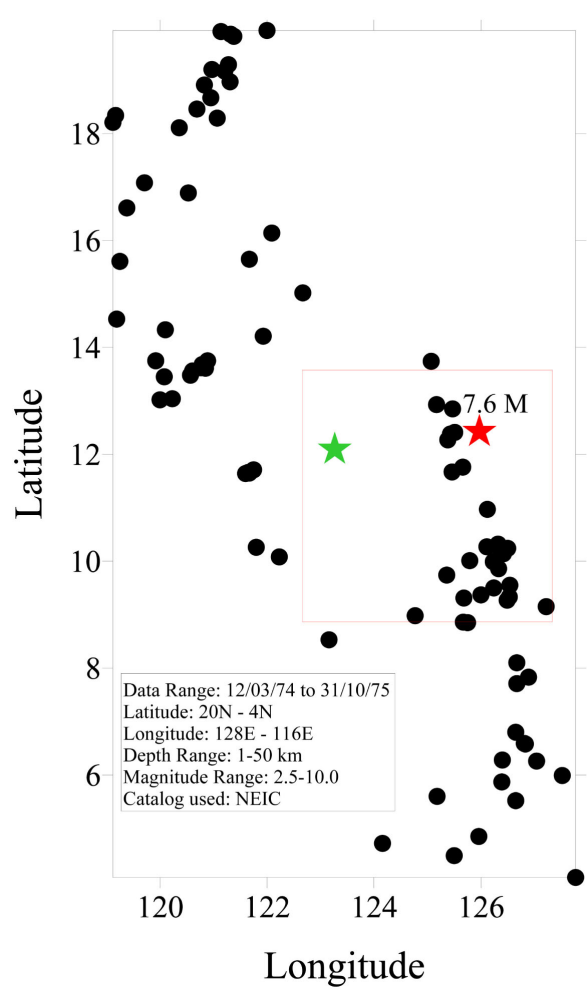

Figure 13. Philippine earthquake of 31/10/75 with analyzed seismicity indicated by black circles. The location of dynamic epicenter $\mathrm{DEM}_{22}$ indicated with the green color star, while the red color star indicates the epicenter of the mainshock occurred.

Seismicity analysis with this model shows interesting results for short-term forecasting. The epicenter of a strong EQ can be determined with an accuracy of less than $25 \%$ of the size of the analyzed area.

Back-testing shows that the model can localize $55 \%$ of the critical areas that may be affected by the epicenter of a strong EQ.

\subsection{Dynamic Epicenter Model $11\left(\mathrm{DEM}_{11}\right)$}

The model presents a similar procedure to the previous one, but it uses the last 10 earthquakes occurred in the considered area in order to predict the short-term trend of the analyzed data and the position of the epicenter of the expected EQ.

The model requires the decreasing order of the latitude and longitude data and the subsequent calculation the best-fit line.

The midpoint of the best-fit line, calculated for both longitude and latitude, provides the coordinates of the expected EQ.

The procedure includes the following calculation steps:

Step 1. Sort in descending order the last 10 latitude values and calculate the best-fit line;

Step 2. Calculate the latitude value $\left(\mathrm{LAT}_{11}\right)$ of the 11th value (point n11) using the equation of the best fit line;

Step 3. Calculate on the best fit line the average value of the eleven values (represented by point n.6) of latitude $\left(\mathrm{LAT}_{\mathrm{M}}\right)$ that define the coordinates of the 
epicenter of the expected earthquake (Figure 14);

Step 4. Repeat the procedure indicated in steps 1 - 3 using the longitude values (Figure 15);

Step 5. Report the $\left(\mathrm{LONG}_{\mathrm{M}}\right)$ and $\left(\mathrm{LAT}_{\mathrm{M}}\right)$ coordinate point on the epicenter plan (Figure 16).

Back-testing shows that the model can locate $55 \%$ of the critical areas that may be affected by the epicenter of a strong EQ.

\subsection{Nine Dynamic Areas Model (NDAM)}

The epicenter of a future EQ can be determined based on the fluctuations of the latitude and longitude values in time and space, with good precision and using filters that reduce the error.

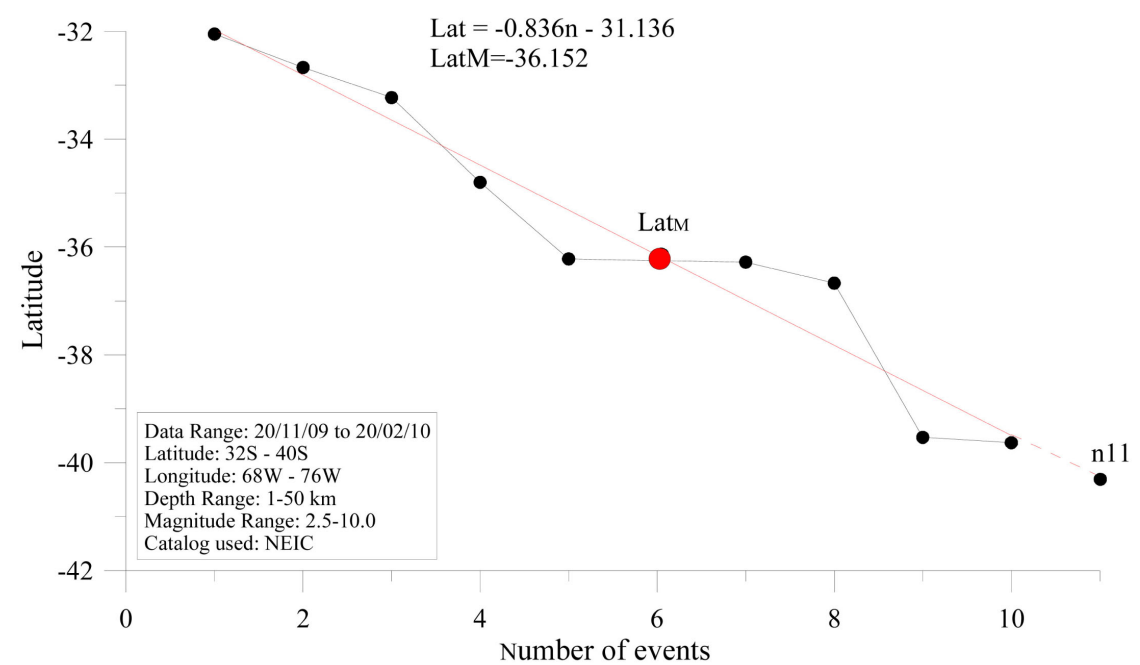

Figure 14. Decreasingly ordered data and calculation of mean latitude value. 2010 Chile earthquake.

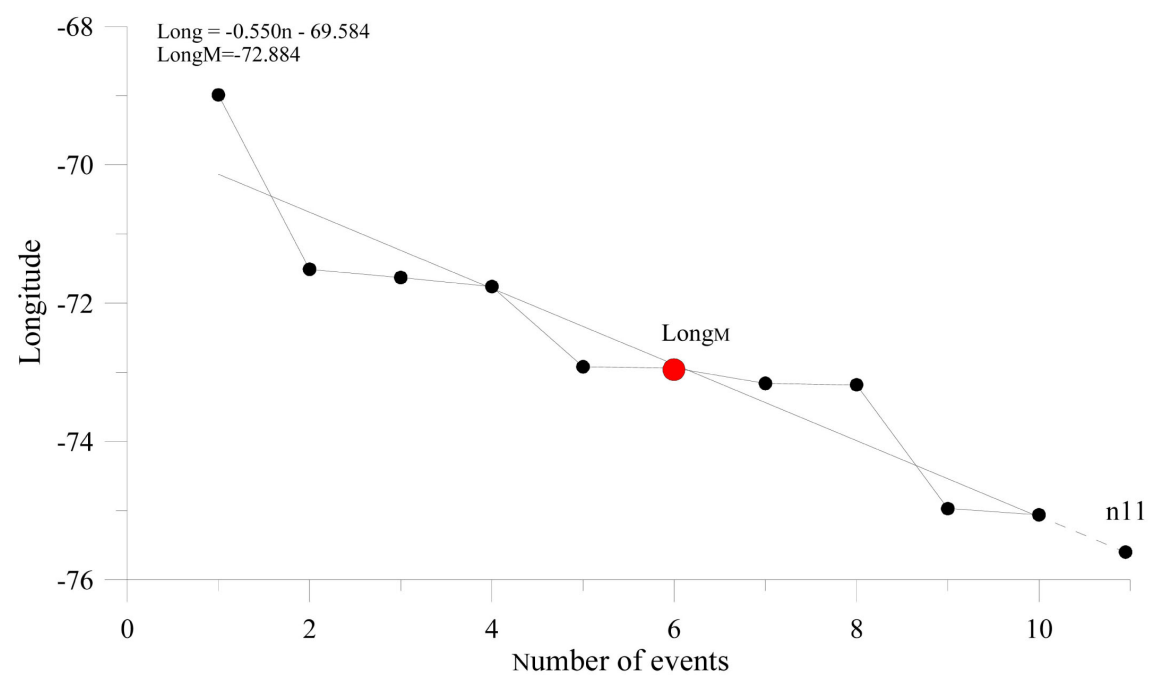

Figure 15. Decreasingly ordered data and calculation of the average longitude value. 2010 Chile earthquake. 


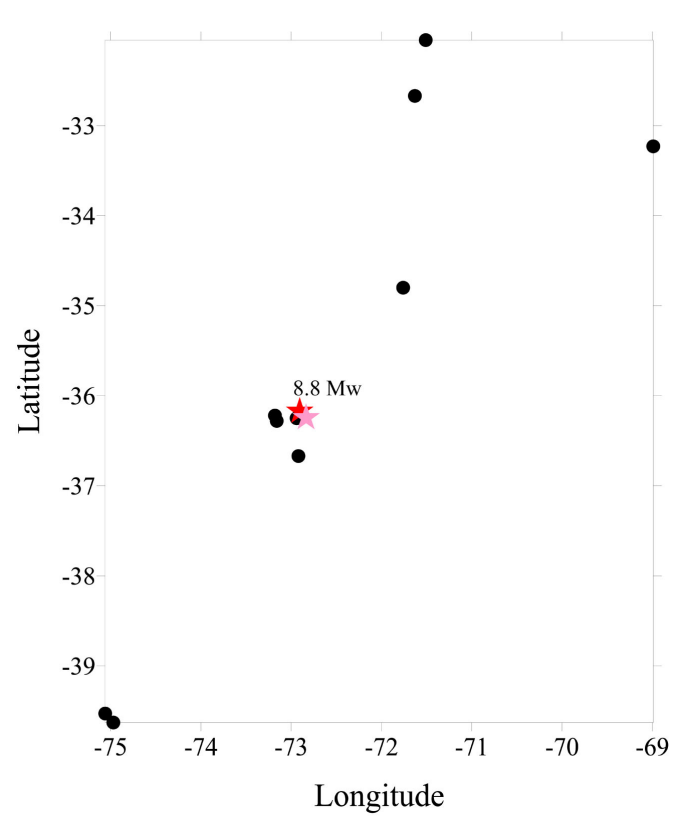

Figure 16. Chile earthquake of 27/02/2010 with the analyzed seismicity indicated with black circles. Location of the dynamic epicenter. The red color star indicates the epicenter of the mainshock that occurred, while the pink color star indicates the calculated DEM11 dynamic epicenter.

In particular, the position of the latitude and longitude values allows, thanks to their fluctuation in space and time, to make evident the position of some more significant epicentral areas to be compared also to the position of seismogenic source.

This methodology represents a good complement to other techniques used for the research of the epicenter and allows to obtain a greater confidence with the study area.

The NDAM model that involves the definition of nine epicenter areas is based on the following assumptions:

1) Movements of latitude and longitude values are subjected to $\wedge$ or $\vee$ swings representing opposing maximum and minimum peaks;

2) Most of the epicenters of strong EQ tend to be located near the midline of latitude and longitude values.

The first operation to be performed on the graphs of the longitude values is the recognition of the $\wedge$ swings (blue circles) and the $\vee$ swings (red circles) which is done on the basis of the maximum and minimum values, identifying them with circles of different colors (Figure 17).

The identified vertices represent an important structure to determine the most sensitive areas that could be affected by a strong EQ.

At this point it is necessary to perform the following steps of calculation:

Step 1. Calculate the average value $A_{1 b}$ (blue colored line) of the blue circles;

Step 2. Calculate the average value $A_{1 r}$ (red color line) of the red circles;

Step 3. Calculate the average value $A_{1 n}$ (black color line) of the red and blue circles; 


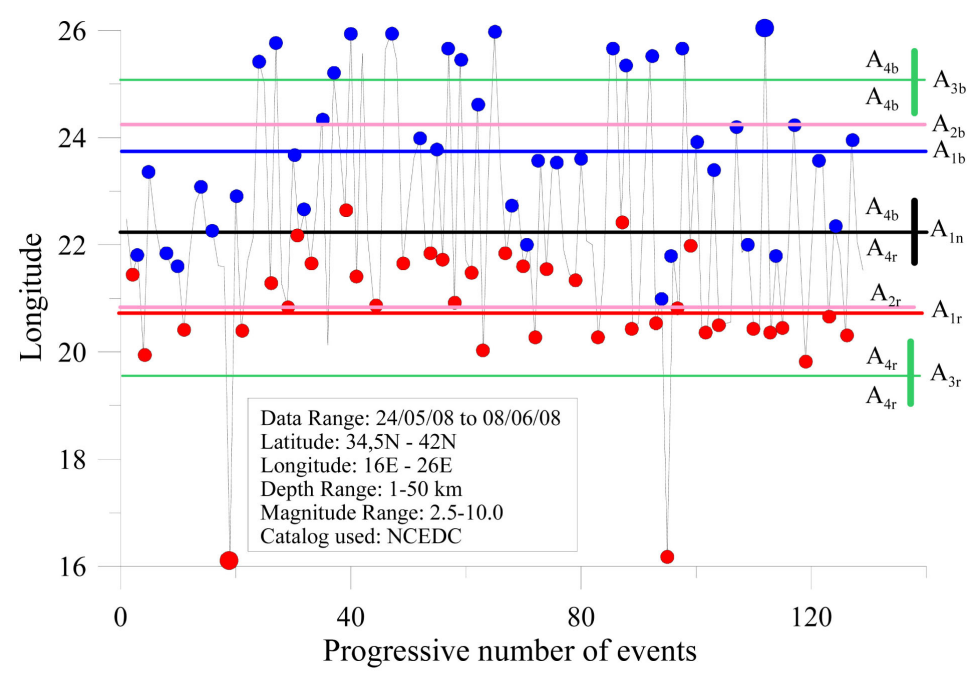

Figure 17. Greece Earthquake of 08/06/2008. Progressive change in longitude values and application of the NDAM model.

Step 4. Calculate the average value $\mathrm{A}_{2 \mathrm{~b}}$ (lower pink color line) of blue and red circles above the black line;

Step 5. Calculate the average value $A_{2 r}$ (upper pink color line) of red and blue circles below the black line;

Step 6. Calculate the average value $A_{3 b}$ (upper green color line) of blue and red circles above the blue color line $\left(\mathrm{M}_{1 \mathrm{~b}}\right)$;

Step 7. Calculate the average value $\mathrm{A}_{3 \mathrm{r}}$ (lower green color line) of red and blue circles below the red color line $\left(\mathrm{M}_{1 \mathrm{r}}\right)$;

Step 8. Calculate the average difference $\mathrm{A}_{4 \mathrm{~b}}$ between the upper green color line $\left(A_{3 b}\right)$ and the upper blue and pink color lines $\left(A_{1 b}\right.$ and $\left.A_{2 b}\right)$ using the following formula:

$$
A_{4 b}=a b s\left(\frac{\frac{A_{3 b}-A_{1 b}}{2}+\frac{A_{3 b}-A_{2 b}}{2}}{2}\right)
$$

Step 9. Add and subtract to the average $A_{3 b}$ (upper green line) the quantity $\mathrm{A}_{4 \mathrm{~b}}$;

Step 10. Calculate the average $A_{4 r}$ difference between the lower green color line $\left(\mathrm{A}_{3 \mathrm{r}}\right)$ and the lower red and pink color lines $\left(\mathrm{A}_{1 \mathrm{r}}\right.$ and $\left.\mathrm{A}_{2 \mathrm{r}}\right)$ using the following formula:

$$
A_{4 r}=a b s\left(\frac{\frac{A_{3 r}-A_{1 r}}{2}+\frac{A_{3 r}-A_{2 r}}{2}}{2}\right)
$$

Step 11. Add and subtract to the average $\mathrm{A}_{3 \mathrm{r}}$ (lower green color line) the quantity $\mathrm{A}_{4 \mathrm{r}}$;

Step 12. Add to the average $A_{1 n}$ (black color line) the quantity $A_{4 b}$ above and $\mathrm{A}_{4 \mathrm{r}}$ below; 
Step 13. Repeat the procedure in steps 1 - 12 using the latitude values.

The procedure allows you to define nine rectangular epicentral areas (Figure 18) with the probability of a strong EQ occurring inside.

The dimensions of the areas (width and length) are calculated in the following:

- upper areas $\left(\mathrm{A}_{4 \mathrm{~b}}+\mathrm{A}_{4 \mathrm{~b}}\right)$;

- middle areas $\left(\mathrm{A}_{4 \mathrm{~b}}+\mathrm{A}_{4 \mathrm{r}}\right)$;

- lower areas $\left(\mathrm{A}_{4 \mathrm{r}}+\mathrm{A}_{4 \mathrm{r}}\right)$.

Where, $A_{4 b}$ and $A_{4 r}$ are the quantities calculated with Formulas (1) and (2).

The red-colored areas are those which, from a statistical point of view, contain the greatest number of strong earthquakes and therefore represent those of greater danger compared to the green-colored areas.

If we consider the areal extension, then the six areas with less extension are those with greater hazard, while considering the proximity, the six closest areas are those with greater hazard (areas 1, 2, 3, 4, 5 and 6).

Back-testing shows that the model can be used in the short term to locate over $85 \%$ of the critical areas that may be affected by a strong EQ.

\subsection{Best Fit Filter (BFF)}

This type of filter allows to reduce the number of areas identified with the previous model by identifying the most dangerous epicentral belt.

The procedure is the following: from the vertices $A, B, C, D$ (red circles in Figure 19) of the green areas it is necessary to draw the parallels to the best fit line of all the events considered in the analysis area, attributing the red color to the internal parallels and the green color to the external ones. The expected

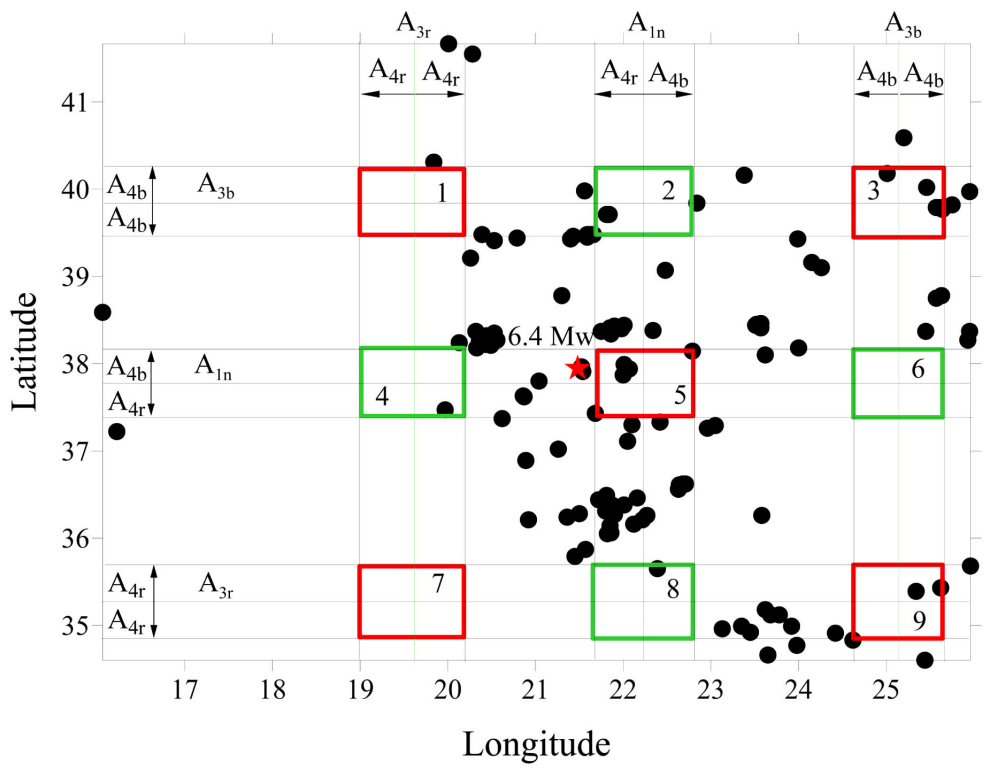

Figure 18. Procedure applied to the $08 / 06 / 2008$ Greece earthquake seismic sequence. The map shows areas colored according to hazard. The red colored star indicates the actual epicenter of the EQ. 


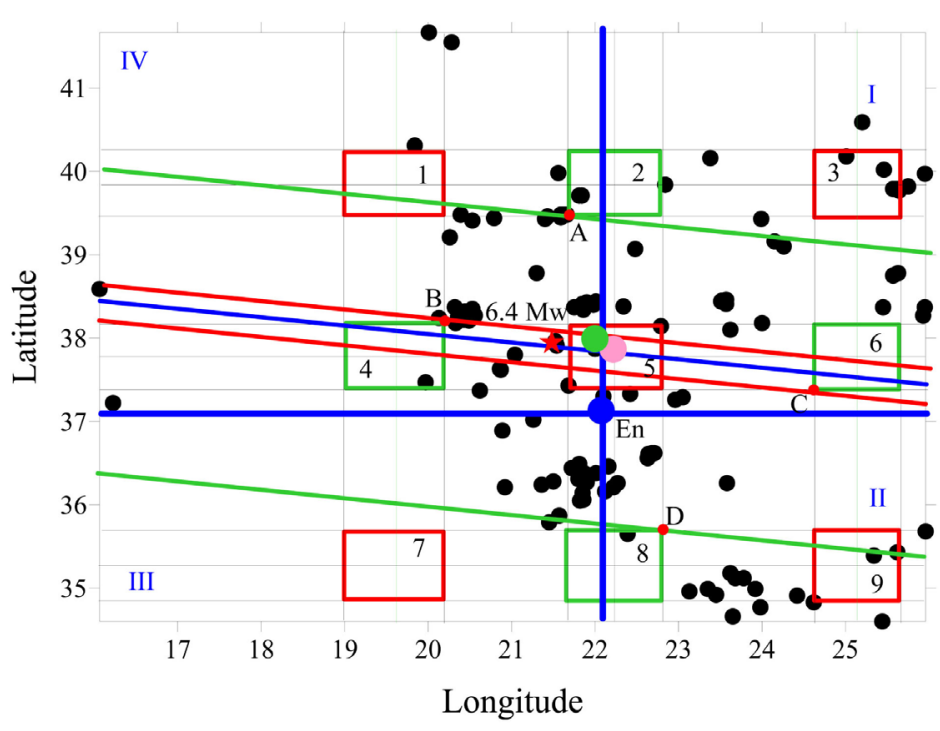

Figure 19. Procedure applied to the $08 / 06 / 2008$ Greece earthquake seismic sequence. The map shows the hazard bands. The solid blue colored circle (En) indicates the last recorded earthquake. The quadrants are indicated with the letters I, II, III and IV in blue color. The red star indicates the epicenter of the earthquake. The pink and green colored circles indicate the dynamic epicenters calculated using the $\mathrm{DEM}_{11}$ and $\mathrm{DEM}_{22}$ procedure.

epicenter is placed more frequently within the internal parallels of red color or where the parallels are closer (parallels of red color and parallel of upper green color).

Observing the figure, it is possible to easily identify the most dangerous areas of red color (n.5) and green (4 and 6) placed within the band, while areas 3, 7 are the least dangerous.

In addition, in many seismic sequences it is possible to improve the position of the areas related to the epicenter of the expected earthquake, making the epicenter of the last earthquake recorded in the analyzed area coincide with the center of the area of red or green color closest to it and then it is necessary to translate all other areas (Figure 20).

\subsection{Last Epicenter Filter (LEF)}

This type of filter allows identifying the sector that may be affected by an EQ in the future using the last earthquake occurred in the analyzed region and the position of the dynamic epicenters $\mathrm{DEM}_{11}$ and $\mathrm{DEM}_{22}$.

The procedure to plot the sectors is as follows:

Step 1. Divide the study area into four quadrants (I, II, III, IV) taking the last recorded epicenter (En) as reference (blue colored circle);

Step 2. Draw the straight lines (cyan-colored lines) passing between the last epicenter En and the center of each area (Figure 21).

The quadrant where the dynamic epicenters $\mathrm{DEM}_{11}$ and $\mathrm{DEM}_{22}$ (pink and green circles) fall simultaneously is the one with the highest probability of occurrence of a strong earthquake ( $91 \%$ of the analyzed earthquakes). 


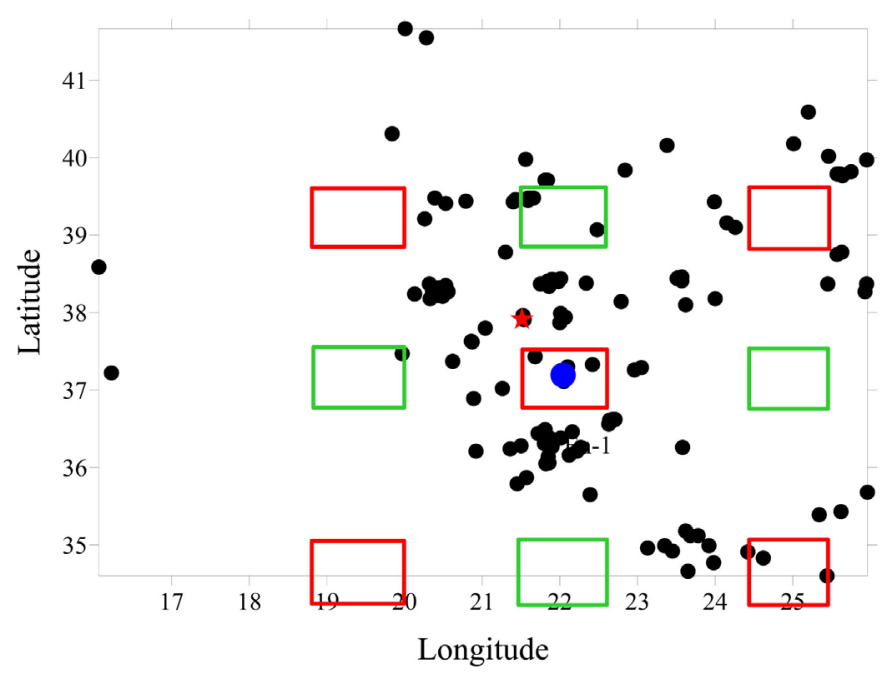

Figure 20. Procedure applied to the seismic sequence of the 08/06/2008 Greece earthquake. The map shows the areas colored according to hazard and transported with respect to the last recorded earthquake (solid blue circle). The red colored star indicates the epicenter of the earthquake.

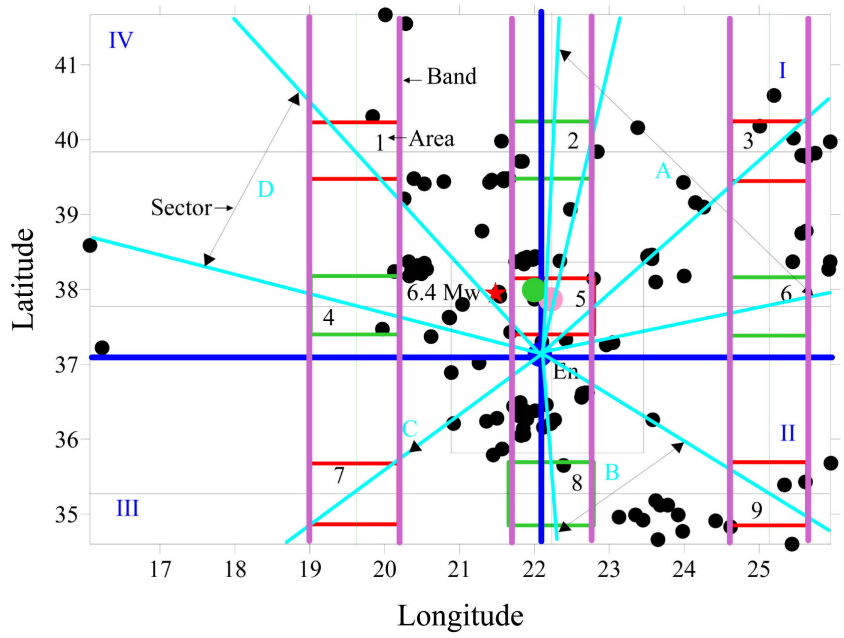

Figure 21. LEF filter procedure applied to the $08 / 06 / 2008$ Greece earthquake seismic sequence. The fourth quadrant is the most likely to be affected by an EQ. The red star indicates the epicenter of the earthquake. The solid pink and green circles indicate the dynamic epicenters calculated with the $\mathrm{DEM}_{11}$ and $\mathrm{DEM}_{22}$ procedure. The letters $\mathrm{A}, \mathrm{B}, \mathrm{C}$ and $\mathrm{D}$ indicate the sectors.

In cases where the $\mathrm{DEM}_{11}$ and $\mathrm{DEM}_{22}$ dynamic epicenters are inside two different quadrants or near the boundary, both quadrants are chosen. In some earthquake sequences, the quadrant opposite to the one, where $\mathrm{DEM}_{11}$ and $\mathrm{DEM}_{22}$ dynamic epicenters are inside, are affected by a strong EQ.

The probability of occurrence of a strong earthquake is greatest in one of the four sectors identified by the filter or/and in one of the three violet color bands.

If we consider the proximity of the areas (center area) in relation to the last epicenter (En), the six closest areas are those with the highest hazard (areas 1, 2, $4,5,7$ and 8$)$. 
Figure 22 shows the results of the NDAM procedure applied to the Iran earthquake of 10/05/1997. The areas No. 1, 2, 3, 4, 5 and 6 of smaller extent are those where the occurrence of a strong EQ is most likely.

\subsection{Pairs of Earthquakes Model (PEM)}

This model assumes that the future earthquake has located in an area with a higher concentration of epicenters and/or where the epicenters are not far away.

The algorithm, very efficient in terms of calculation time and accuracy, identifies in the analyzed region, small areas that may be affected by the large earthquake in the future.

The calculation procedure uses a prefixed number of seismic events and based on a principle of spatial "proximity" Figure 19, analyzes each pair of earthquakes having a predefined distance.

By default, we chose to use the last forty earthquakes and analyze those that have an interdistance equal to $35 \mathrm{~km}$ (default $40 \mathrm{EQ} \times 35 \mathrm{~km}$ ).

In the calculation practice, the last forty earthquakes recorded in the studied area are used and of these, the pairs with an interdistance less than $35 \mathrm{~km}$ are analyzed.

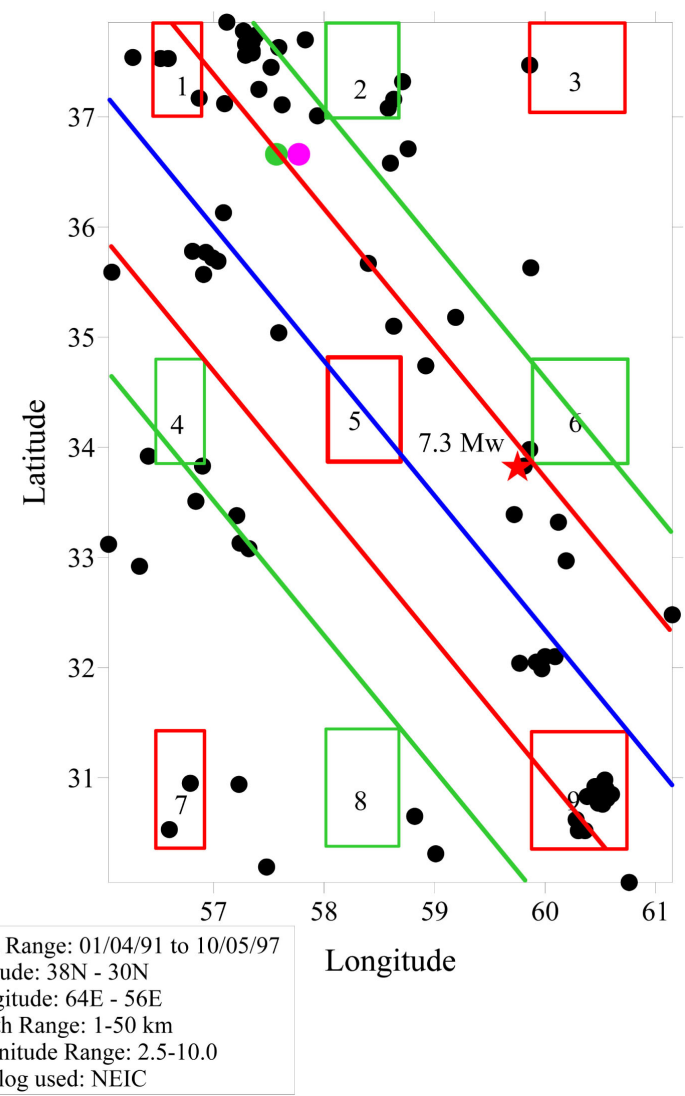

Figure 22. Procedure applied to the Iran earthquake seismic sequence of 10/05/1997. The map shows the areas colored according to hazard. The red colored star indicates the epicenter of the earthquake. The pink and green colored circles indicate the dynamic epicenters calculated with the $\mathrm{DEM}_{11}$ and $\mathrm{DEM}_{22}$ procedure. 
This simple operation will allow visualizing with colors the areas with smaller interdistance in the studied region (for example in the map the areas where the epicenter pairs have a smaller distance can be indicated with a specific color such as red).

In the back-tests performed, $84 \%$ of the epicenters of future earthquakes were identified and with a small number of areas, using a default value of 40 earthquakes and inter-pair interdistance of $35 \mathrm{~km}$.

To obtain a higher percentage, it is necessary to use an earthquake number of 70 and inter-pair interdistance of $50 \mathrm{~km}$.

Increasing the default values implies, however, an increase in the number of potential areas on which the epicenter of the expected earthquake may fall.

The calculation sequence of the PEM algorithm is as follows:

Step 1 . The last $\mathrm{n}$ earthquakes are analyzed and the pairs having an interdistance between the epicenters equal or different than $\mathrm{D}=35 \mathrm{~km}$ are chosen;

Step 2. Calculate the average value of latitude and longitude of the selected pairs;

Step 3. Construct the map of the epicenters of the pairs assigning to the $Z$ coordinate the value of the minimum distance calculated in step 1;

Step 4. Report in the map the dynamic epicenters $\mathrm{DEM}_{11}$ and $\mathrm{DEM}_{22}$.

Figures 23-28 show the results obtained by applying the model to seismic sequences that happened before strong earthquakes occurred in Greece, USA, Italy and Japan, using a different number of events and interdistance between epicenter pairs. The colored red areas are those where the epicenter pairs with smaller interdistance and the most dangerous.

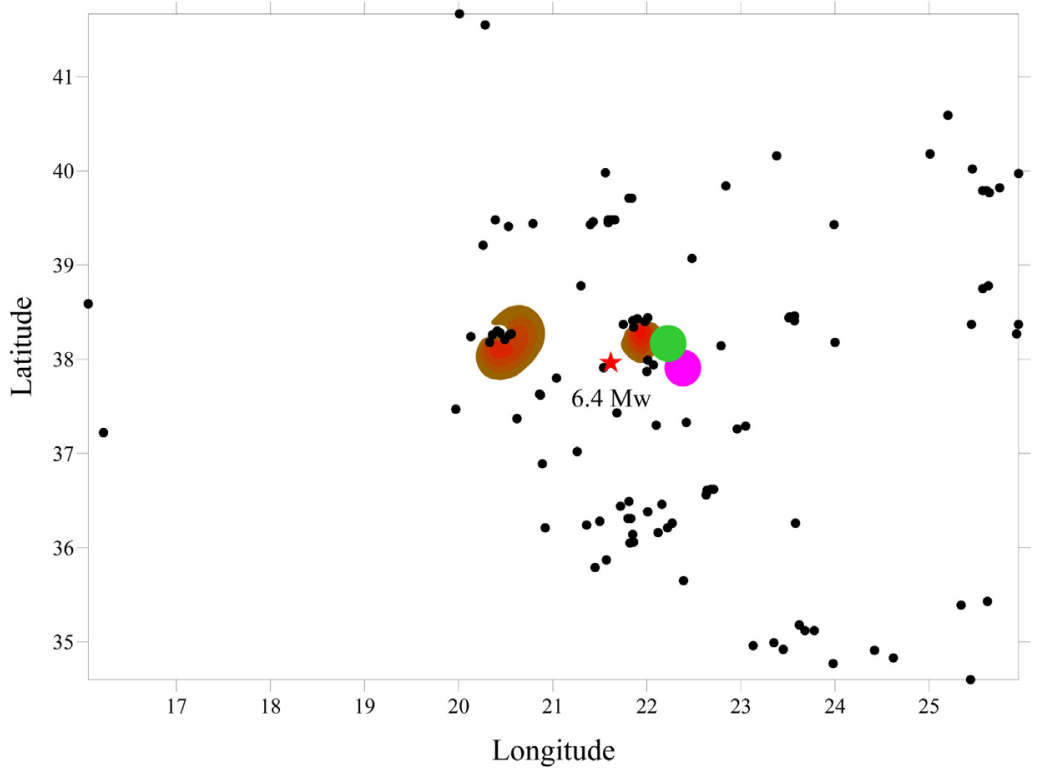

Figure 23. Procedure applied to the $08 / 06 / 2008$ Greece earthquake seismic sequence. Initial input data 30 earthquakes and minimum inter-pair interdistance $20 \mathrm{~km}$. The map shows areas colored according to hazard. The red star indicates the actual epicenter, the pink and green circles indicate the dynamic epicenters $\mathrm{DEM}_{11}$ and $\mathrm{DEM}_{22}$. 


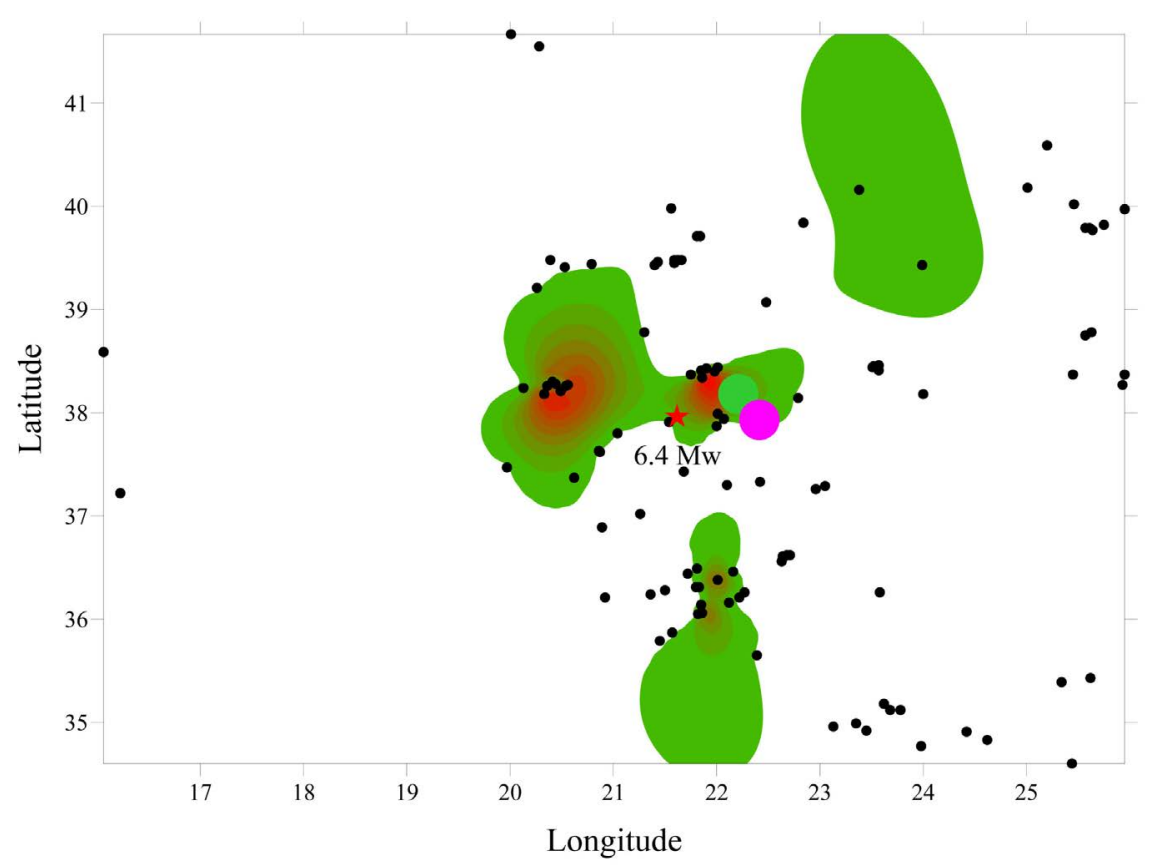

Figure 24. Procedure applied to the 08/06/2008 Greece earthquake seismic sequence. Initial input data 30 earthquakes and minimum inter-pair interdistance $100 \mathrm{~km}$. The map shows areas colored according to hazard. The red star indicates the actual epicenter, the pink and green circles indicate the dynamic epicenters $\mathrm{DEM}_{11}$ and $\mathrm{DEM}_{22}$.

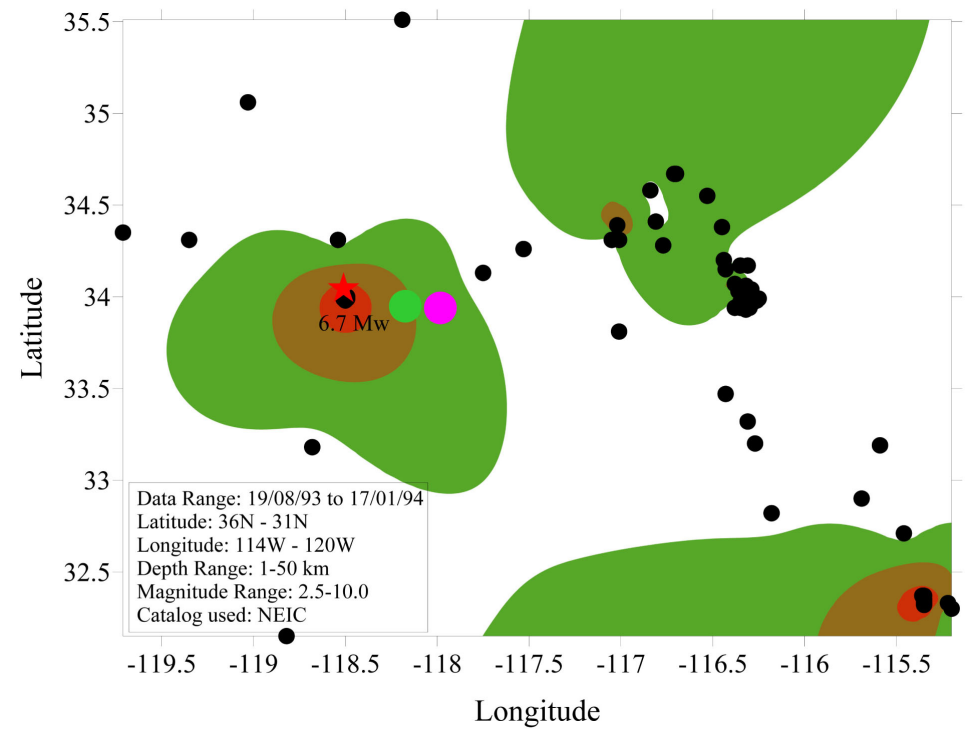

Figure 25. Procedure applied to the Landers (California) earthquake seismic sequence of 17/01/1994. Initial input data 40 earthquakes and minimum inter-pair interdistance 35 $\mathrm{km}$. The map shows areas colored according to hazard. The red star indicates the actual epicenter, the pink and green circles indicate the dynamic epicenters $\mathrm{DEM}_{11}$ and $\mathrm{DEM}_{22}$.

\subsection{Dynamic Dials Model (DDM)}

This quick and simple forecasting method analyzes the events falling in sixteen rectangular areas of different size obtained by subdividing the analyzed region (Figure 29). 


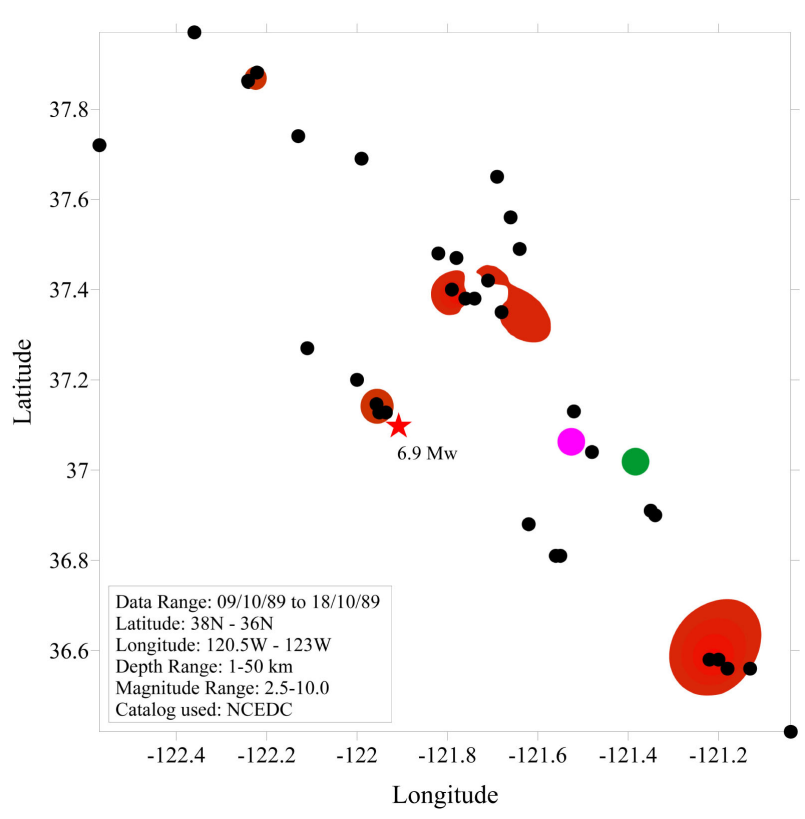

Figure 26. Procedure applied to the seismic sequence of the Loma Prieta (California) earthquake of 17/10/1989. Initial input data 40 earthquakes and minimum inter-pair interdistance $35 \mathrm{~km}$. The map shows areas colored according to hazard. The red star indicates the actual epicenter, the pink and green circles indicate the dynamic epicenters $\mathrm{DEM}_{11}$ and $\mathrm{DEM}_{22}$.

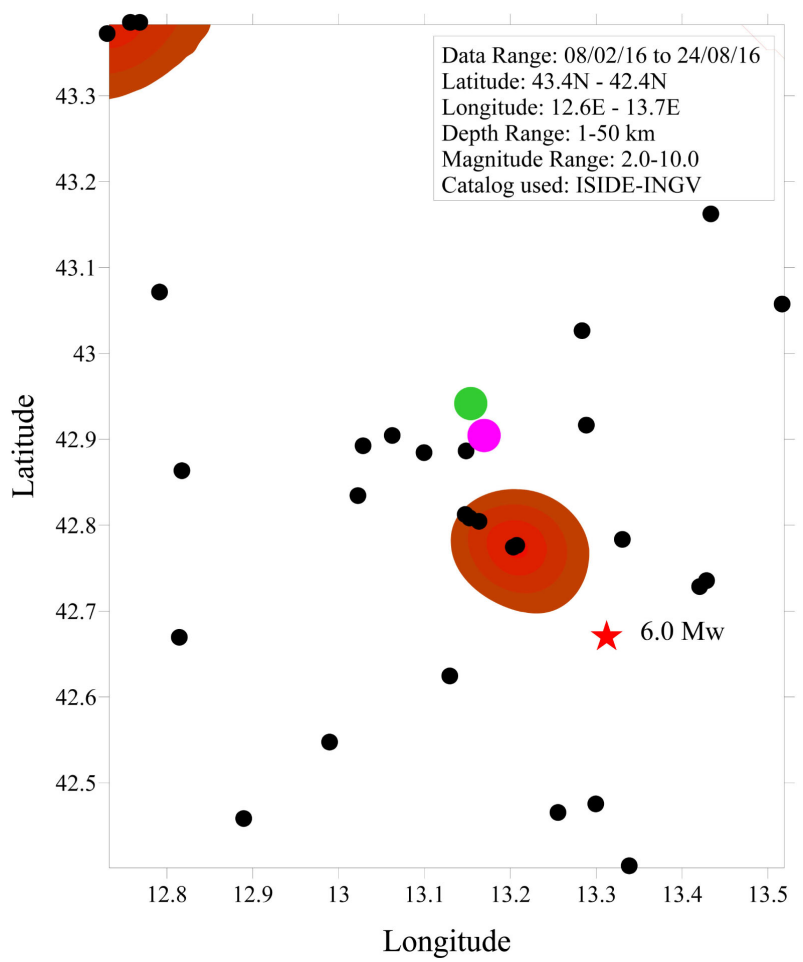

Figure 27. Procedure applied to the Amatrice (Italy) earthquake seismic sequence of 24/08/2016. Initial input data 40 earthquakes and minimum inter-pair interdistance 35 $\mathrm{km}$. The map shows areas colored according to hazard. The red colored star indicates the actual epicenter, the pink and green colored filled circles indicate the dynamic epicenters $\mathrm{DEM}_{11}$ and $\mathrm{DEM}_{22}$. 


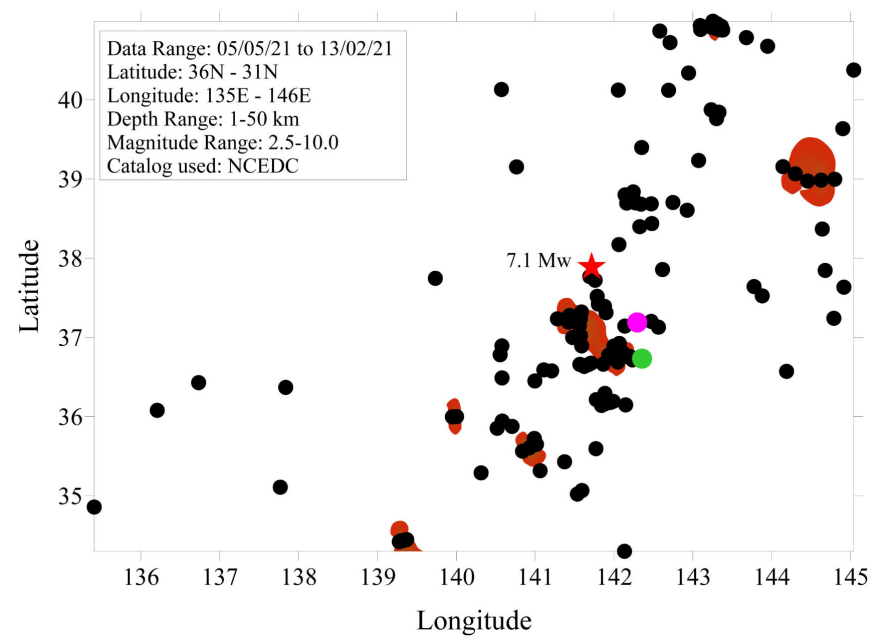

Figure 28. Procedure applied to the Japan earthquake seismic sequence of 13/02/2021. Initial input data 40 earthquakes and minimum inter-pair interdistance $35 \mathrm{~km}$. Map shows areas colored according to hazard. The red colored star indicates the EQ epicenter, the pink and green colored circles indicate the dynamic epicenters $\mathrm{DEM}_{11}$ and $\mathrm{DEM}_{22}$.

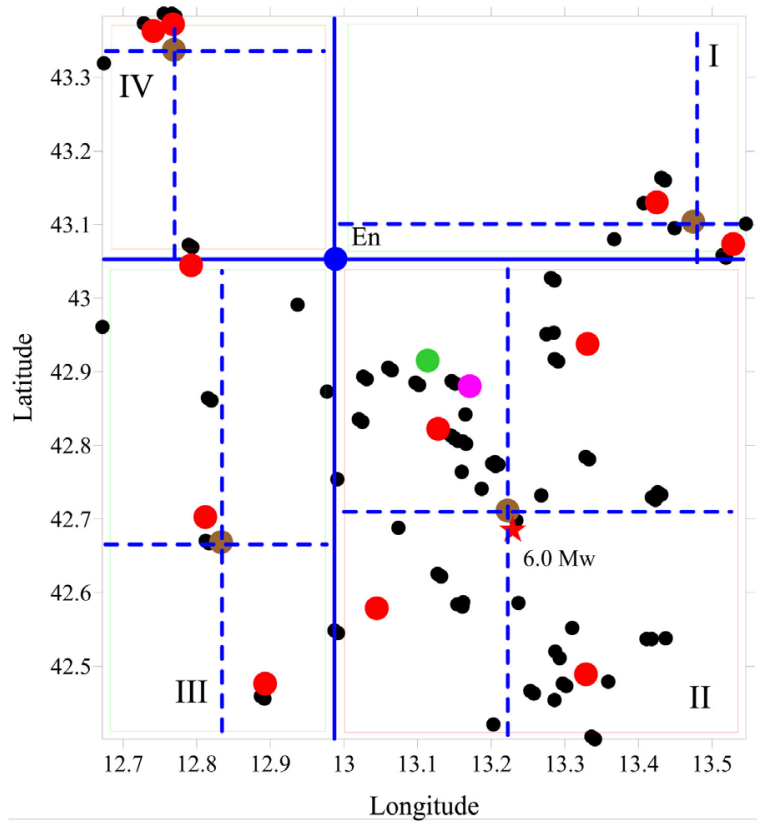

Figure 29. Procedure applied to the seismic sequence of the Amatrice (Italy) earthquake of 24/08/2016. The red color star indicates the epicenter of the EQ.

Even if it will not be possible to establish with precision the epicenter of the future EQ, the procedure is useful to predict the epicenter area.

The calculation method involves the subdivision of the analyzed region into four quadrants of different size and then, a subsequent subdivision of the four quadrants in order to obtain sixteen areas.

The main steps of the DDM algorithm can be summarized as follows:

Step 1. Divide the study area into four quadrants (I, II, III, IV) taking as reference the last recorded epicenter (En) (blue colored circle); 
Step 2. Calculate the average epicenter of each quadrant (the arithmetic mean of the latitude and longitude values indicated with the brown circle) using all the epicenters falling in the quadrant;

Step 3. Repeat the procedure indicated in step 1 to obtain sixteen sub-quadrants (blue dashed lines) and taking as reference the average epicenter calculated in step 2;

Step 4. Calculate the average epicenter of each new sub-quadrant (red circle) using all the epicenters in the sub-quadrant;

Step 5. Report in the map the dynamic epicenters $\mathrm{ED}_{11}$ and $\mathrm{ED}_{22}$.

The brown, red, pink, green and blue circles are the points where the probability of occurrence of a strong earthquake is highest.

This forecasting algorithm based on dividing the region into quadrants can predict $85 \%$ of EQs.

\subsection{Sector Filter (SF)}

This type of filter allows to identify the four highest hazard epicentral sectors of a region and to reduce the number of potential epicenters calculated with the models described above.

The procedure for identifying sectors can be summarized as follows:

Step 1. Draw the straight line (red color line) passing between the last epicenter En (blue color circle) and the midpoint of all epicenters selected with the PEM model (step 1) falling in the quadrant (Figure 30);

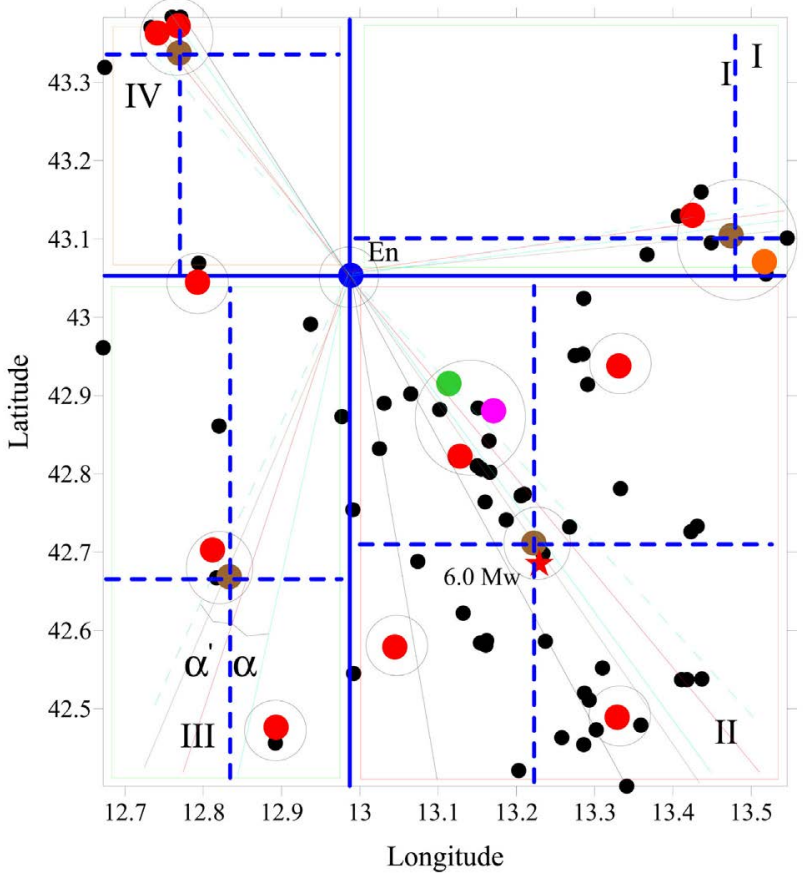

Figure 30. Procedure applied to the seismic sequence of the Amatrice (Italy) earthquake of 24/08/2016. The second quadrant is the most likely to be affected by an EQ. The red colored star indicates the epicenter of the earthquake, the red colored circles indicate the area most likely to be affected by a strong earthquake. 
Step 2. Draw the line (brown line) between the last epicenter En (blue circle) and the midpoint (arithmetic mean) of all the epicenters of the analyzed series falling in the quadrant (brown circle);

Step 3. Calculate the average angle of all segments between the last epicenter and the epicenters in each quadrant and then draw the ray with origin in the last epicenter (light blue line);

Step 4. Calculate the angle between the light blue and red lines ( $\alpha$ );

Step 5. Draw the ray passing through the last epicenter inclined of an angle $\alpha^{\prime}$ $=\alpha$ (dashed light blue line);

Step 6. Repeat the same procedure in all quadrants;

Step 7. Draw straight lines from the last to the penultimate and third last epicenter (black lines);

Step 8. Select the areas that include the points identified with the DDM model (brown, red, pink, green and blue colored circles) closest to the sector identified by the filter and the last epicenter (En) of the analyzed series (black colored circled areas).

The quadrant where the dynamic epicenters $\mathrm{DEM}_{11}$ and $\mathrm{DEM}_{22}$, the sector included in it and the areas closest to the sector (areas circled in red), are those with a higher probability of occurrence of a strong earthquake. Figure 31 shows the results obtained with this filter applied to the 2016 Amatrice (Italy) earthquake seismic sequence.

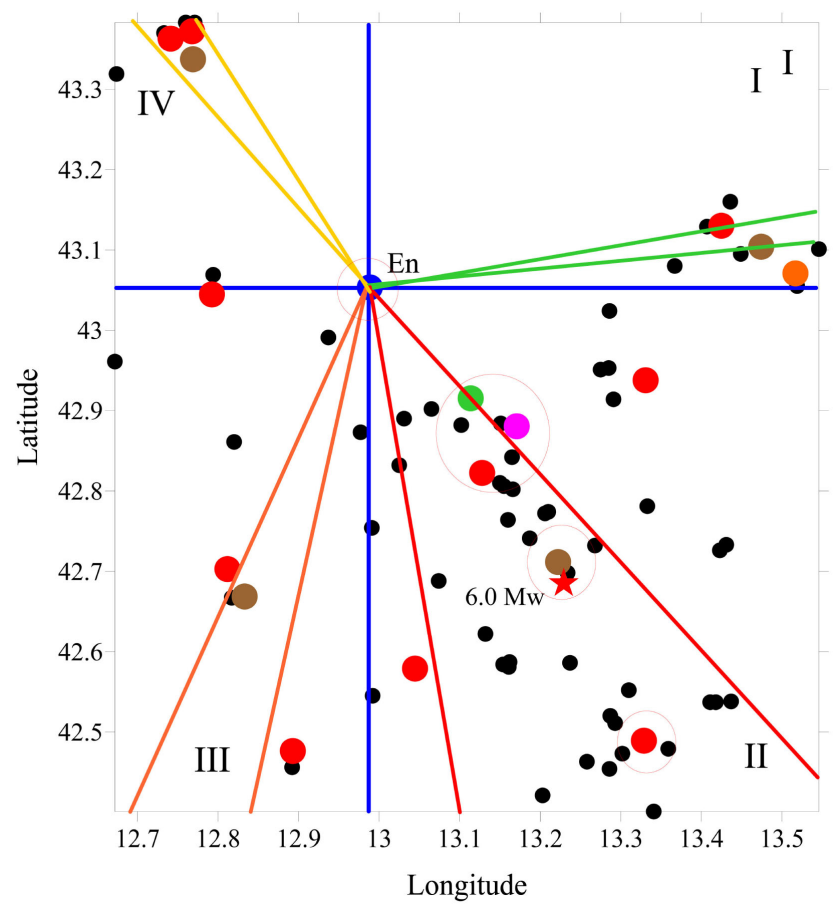

Figure 31. Procedure applied to the seismic sequence of the Amatrice (Italy) earthquake of 24/08/2016. The red, orange, yellow and green half-lines indicate the sectors. The second quadrant is the most likely to be affected by an EQ. The red colored star indicates the epicenter of the earthquake, the red colored circles indicate the area most likely to be affected by a strong earthquake. 


\section{Conclusions}

A better understanding of the spatial and temporal distribution of the epicenters of earthquakes that occurred in a region before a large earthquake seems crucial for predicting the area that may be affected by the earthquake in the short term.

Observations of fluctuations in seismicity show that before a lot of large magnitude events, the size of the area of activity decreases over time.

The described method shows the spatial distribution of the events where pairs of earthquakes occur a few kilometers away from the actual epicenter of the main earthquake. The epicenter of the future earthquake is close to the last occurred earthquake in the $40 \%$ of the seismic sequences analyzed.

These observations have allowed to design some spatial prediction models that can help to estimate the position of the epicentral area of a future earthquake by analyzing a large territory.

Back-tests show that the developed models can be used in the short term to localize about $85 \%$ of the critical areas where a strong EQ may occur.

For the remaining $15 \%$ of the examined earthquakes it has been difficult to locate the epicentral area with acceptable precision even if for some of them an improvement of the results has been noticed by using more models simultaneously.

Given the accuracy of the models developed, the results obtained may be helpful in developing new prediction methods.

\section{Conflicts of Interest}

The authors declare no conflicts of interest regarding the publication of this paper.

\section{References}

[1] Du, A., Huang, Q. and Yang, S. (2002) Epicenter Location by Abnormal ULF Electromagnetic Emissions. Geophysical Research Letters, 29, 94-1-94-3. https://doi.org/10.1029/2001GL013616

[2] Zhan, Z., Wei, S., Ni, S. and Helmberger, D. (2011) Earthquake Centroid Locations Using Calibration from Ambient Seismic Noise. Bulletin of the Seismological Society of America, 107, 1438-1445. https://doi.org/10.1785/0120100118

[3] Zhu, W., Sun, L. and Zhu, X. (2012) New Estimation Algorithm for Epicenter Location of Low Frequency Seismograms. Proceedings of the 2012 International Conference on Systems and Informatics (ICSAI), Yantai, 19-20 May 2012, 1706-1710. https://ieeexplore.ieee.org/abstract/document/6223371 https://doi.org/10.1109/ICSAI.2012.6223371

[4] Knopoff, L., Kagan, Y.Y. and Knopoff, R. (1982) B-Values for Fore- and Aftershocks in Real and Simulated Earthquakes Sequences. Bulletin of the Seismological Society of America, 72, 1663-1676.

[5] Molchan, G.M. and Dmitrieva, O. (1990) Statistical Analysis of the Results of Earthquake Prediction, Based on Bursts of Aftershocks. Physics of the Earth and Planetary Interiors, 61, 99-112. https://doi.org/10.1016/0031-9201(90)90098-I

[6] Molchan, G.M., Konrod, T.L. and Nekrasova, A.K. (1999) Immediate Foreshocks: 
Time Variation of the B-Value. Physics of the Earth and Planetary Interiors, 111, 229-240. https://doi.org/10.1016/S0031-9201(98)00163-0

[7] Dodge, D.D., Beroza, G.C. and Ellsworth, W.L. (1996) Detailed Observations of California Foreshock Sequence: Implication for the Earthquake Initiation Process. Journal of Geophysical Research: Solid Earth, 101 22371-22392.

https://agupubs.onlinelibrary.wiley.com/doi/abs/10.1029/96JB02269 https://doi.org/10.1029/96JB02269

[8] Bowman, D.D., Ouillon, G., Sammis, G., Sornette, A. and Sornette, D. (1998) An Observational Test of the Critical Earthquake Concept. Journal of Geophysical Research: Solid Earth, 103, 24359-24372.

https://agupubs.onlinelibrary.wiley.com/doi/abs/10.1029/98JB00792 https://doi.org/10.1029/98JB00792

[9] Bowman, D.D. and King, G.C.P. (2001) Accelerating Seismicity and Stress Accumulation before Large Earthquakes. Geophysical Research Letters, 28, 4039-4042.

https://agupubs.onlinelibrary.wiley.com/doi/pdf/10.1029/2001GL013022 https://doi.org/10.1029/2001GL013022

[10] King, G.C.P. and Bowman, D.D. (2003) The Evolution of Regional Seismicity between Large Earthquakes. Journal of Geophysical Research, 108, 14-1-14-16. http://www.ipgp.fr/ king/Geoffrey_King/Publications_files/2003\%20King\%20JGR. pdf https://doi.org/10.1029/2001JB000783

[11] Ohnaka, M. (1993) Critical Size of the Nucleation Zone of Earthquake Rupture Inferred from Immediate Foreshock Activity. Journal of Physics of the Earth, 41, 45-46. https://doi.org/10.4294/jpe1952.41.45

[12] Abercombie, R.E. and Mori, J. (1996) Occurrence Patterns of Foreshocks to Large Earthquakes in the Western United States. Nature, 381, 303-307. https://doi.org/10.1038/381303a0

[13] Sarlis, N.V., Skordas, E.S., Varotsos, P.A., Nagao, T., Kamogawa, M. and Uyeda, S. (2015) Spatiotemporal Variations of Seismicity before majorearthquakes in the Japanese Area and Their Relation with the Epicentral Locations. Proceedings of the National Academy of Sciences, 112, 986-989. https://doi.org/10.1073/pnas.1422893112

[14] Riga, G. and Balocchi, P. (2018) Double Earthquakes Classification and Seismic Precursors. Open Journal of Earthquake Research, 7, 1-27. https://doi.org/10.4236/ojer.2018.71001

[15] Stein, S. and Liu, M. (2009) Long Aftershock Sequences within Continents and Implications for Earthquake Hazard Assessment. Nature, 462, 87-89. https://doi.org/10.1038/nature08502

[16] Aki, K. (1956) Some Problems in Statistical Seismology. Zisin, 8, 205-228. https://www.jstage.jst.go.jp/article/zisin1948/8/4/8_4_205/_pdf https://doi.org/10.4294/zisin1948.8.4_205

[17] INGV (2017) 2017a-Centro Nazionale Terremoti, Earthquake List. http://info.terremoti.ingv.it/en

[18] U.S. Geological Survey (USGS) (2020) Search Earthquake Archives. http://earthquake.usgs.gov/earthquakes/search/

[19] Reasenberg, P. (1985) Second-Order Moment of Central California Seismicity, 1969-1982. Journal of Geophysical Research, 90, 5479-5495. http://www.ipgp.fr/ narteau/DATA/OLD/Rasenberg85.pdf https://doi.org/10.1029/JB090iB07p05479 


\section{List of Abbreviations}

$\begin{array}{ll}\text { Abbreviation } & \text { Meaning } \\ \text { FMA } & \text { Foreshocks-mainshock-aftershocks sequence } \\ \text { EQ } & \text { Earthquake } \\ \text { DEM }_{22} & \text { Dynamic Epicenter Model 22 } \\ \text { LONG }_{22} & \text { Longitude of 22nd earthquake } \\ \text { LAT }_{22} & \text { Latitude of 22nd earthquake } \\ \text { DEM }_{11} & \text { Dynamic Epicenter Model 11 } \\ \text { LAT }_{11} & \text { Latitude of 11th earthquake } \\ \text { LONG }_{11} & \text { Longitude of 11th earthquake } \\ \text { NDAM } & \text { Nine Dynamic Areas Model } \\ \text { En } & \text { Last recorded epicenter } \\ \text { BFF } & \text { Best Fit Filter } \\ \text { LEF } & \text { Last Epicenter Filter } \\ \text { PEM } & \text { Pairs of Earthquakes Model } \\ \text { DDM } & \text { Dynamic Dials Model } \\ \text { SF } & \text { Sector Filter }\end{array}$

